\title{
Uso do soro autólogo condicionado e do plasma rico em plaquetas na terapia ortopédica de equinos
}

\section{Autologous conditioned serum and platelet-rich plasma in equine orthopedic therapeutics}

\author{
Cynthia Prado Vendruscolo; Ana Liz Garcia Alves²; Patrícia Monaco Brossi³; \\ Raquel Yvonne Arantes Baccarin ${ }^{4 *}$
}

\begin{abstract}
Resumo
As lesões musculoesqueléticas que ocorrem durante a prática esportiva em equinos são debilitantes e demandam um longo período de tratamento e reabilitação, para muitas vezes obter-se após o tratamento apenas um tecido cicatricial, predispondo à recidiva. Em busca de terapias mais efetivas e da reparação tecidual de melhor qualidade, tem sido estudada a utilização de derivados sanguíneos, como plasma rico em plaquetas e soro autólogo condicionado. Apesar de ambos serem considerados hemoderivados, o soro autólogo condicionado e o plasma rico em plaquetas são produtos distintos com indicações totalmente diferentes para seu uso. Em lesões tendíneas e ligamentares o plasma rico em plaquetas apresenta resultado promissor em estudos clínicos e experimentais. Nas lesões osteoarticulares estes resultados são obtidos tanto com o soro autólogo condicionado como com o plasma rico em plaquetas. A presente revisão tem como objetivo apresentar estudos clínicos e experimentais (in vivo e in vitro) na espécie equina, que auxiliem na escolha do melhor hemoderivado a ser utilizado frente às diferentes lesões musculoesqueléticas.
\end{abstract}

Palavras-chave: Plasma rico em plaquetas, soro autólogo condicionado, tendão, ligamento, articulação, músculo

\begin{abstract}
Musculoskeletal injuries that occur in horses during sports activities are often disabling and require a long period of treatment and rehabilitation, most resulting in scar tissue, predisposing to recurrence. In search of more effective therapies and tissue regeneration, studies have been carried out with blood derivatives - platelet rich plasma and autologous conditioned serum. In spite of both being bloodderived therapies, platelet rich plasma and autologous conditioned serum are distinct products, with equally distinct indications for their use. Platelet rich plasma shows promising results in ligament and tendon injuries in clinical and experimental trials. This occurs also in osteoarticular lesions with both hemoderivates, autologous conditioned serum and platelet rich plasma. This review aims to present clinical and experimental studies (in vivo and in vitro) in the equine species, as an aid for an appropriate therapeutic choice, when hemoderivates are considered for treatment of musculoskeletal lesions.

Key words: Platelet-rich plasma, autologous conditioned serum, tendon, ligament, joint, muscle
\end{abstract}

\footnotetext{
${ }^{1}$ Médica Veterinária residente, Faculdade de Medicina Veterinária e Zootecnia, USP, São Paulo, SP. E-mail: cynthiaimpoluto@ hotmail.com

${ }^{2}$ Prof Adjunta, Faculdade de Medicina Veterinária e Zootecnia, UNESP, Botucatu, SP. E-mail: anaalves@fmvz.unesp.br

${ }^{3}$ Discente de Doutorado, Faculdade de Medicina Veterinária e Zootecnia, USP, São Paulo, SP. E-mail: ptbrossi@uol.com.br

${ }^{4}$ Prof ${ }^{a}$ Associada, Faculdade de Medicina Veterinária e Zootecnia, USP, São Paulo, SP. E-mail: baccarin@usp.br

* Autor para correspondência
} 


\section{Introdução}

O cavalo atleta é submetido a grandes esforços durante o exercício, podendo sofrer lesões ósseas, tendíneas, ligamentares, articulares e musculares, que prejudicam seu desempenho, e dão início a longos e caros tratamentos. Apesar das diferentes terapias, muitas vezes o resultado final é um tecido de baixa qualidade, comprometendo a função da estrutura tratada quando do retorno do cavalo aos treinamentos. A fim de se obter uma cicatrização de melhor qualidade e em menor tempo, tem sido pesquisado o emprego de derivados sanguíneos como o plasma rico em plaquetas (PRP) e o soro autólogo condicionado (ACS).

$\mathrm{O}$ fato de serem livres das restrições e dos testes requeridos para produtos farmacêuticos, e possuírem fácil disponibilidade e alta segurança, pois são compostos de produtos autólogos, fizeram com que estas terapias biológicas autólogas ganhassem rápida popularidade nos últimos cinco a 10 anos. Estas, por sua vez, têm se expandido na clínica de equinos por apresentarem resultados promissores e por não serem consideradas doping.

Ao mesmo tempo, a natureza individualizada destes produtos também dificulta os estudos científicos, pois como são autólogos, não existirão produtos idênticos para serem administrados a diferentes indivíduos.

\section{Derivados Sanguíneos}

Apesar de serem considerados hemoterapias autólogas, o ACS e o PRP são produtos distintos com indicações totalmente diferentes para seu uso. O ACS é conhecido por suas propriedades anti-catabólicas, ou seja, ele inibe a cascata inflamatória desencadeada pela interleucina-1 (IL1), particularmente na osteoartrite (OA), ao invés de reparar diretamente o tecido. É lógico que a prevenção da atividade da IL-1 permite um melhor tecido de reparação endógeno, mas o ACS tem sido mais frequentemente utilizado nos casos de OA crônica e progressiva, do que nos casos de trauma agudo. Por outro lado, a justificativa para o uso do PRP deve-se à presença dos fatores de crescimento contidos nas plaquetas. Estes fatores são fornecidos em altas concentrações no PRP, como agentes anabólicos, para auxiliar ou aumentar a cicatrização de tecidos danificados. Acredita-se que o uso do PRP seja melhor indicado após lesões traumáticas agudas de tecidos musculoesqueléticos (TEXTOR, 2011). Na verdade, a terapia biológica ideal seria aquela que possuísse atividades tanto anabólicas quanto anti-catabólicas.

Meijer et al. (2003) desenvolveram o ACS comercial rico em proteína antagonista do receptor de interleucina -1 (IL-1ra) a partir da coleta asséptica de sangue venoso. Recentemente, estudos demostraram que o ACS também possui fatores de crescimento (WEHLING et al., 2007; HRAHA et al., 2011), mudando o conceito acima relatado.

Assim, o ACS, sob os nomes comerciais de Irap ${ }^{\circledR}$ e Irap II ${ }^{\circledR}$, para uso veterinário, e Orthokine ${ }^{\circledR}$ para uso humano, é um derivado sanguíneo rico em IL1ra, possuindo também em sua constituição alguns fatores de crescimento, como fator de crescimento fibroblástico-1 (FGF-1), fator de crescimento do hepatócito (HGF), fator de crescimento transformante- $\beta 1$ (TGF- $\beta 1$ ) (FRISBIE et al., 2007), fator de crescimento tipo insulina-1 (IGF-1) e fator de crescimento derivado de plaquetas (PDGF) (WEHLING et al., 2007), além de citocinas antiinflamatórias como as interleucinas-10 e -4 (IL-10, IL-4) (MEIJER et al., 2003).

A IL-1ra contida no ACS atua ligando-se aos receptores de interleucina-1 (IL-1) inibindo a cascata inflamatória que resultaria na destruição do tecido. Em artrites reumatóides e osteoartrites, a IL-1 leva à lesão cartilagínea ao estimular a produção de proteases neutras, como as metaloproteinases de matriz(MMPs), pelas células sinoviais e condrócitos (AREND et al., 1998), resultando na quebra do colágeno, glicosaminoglicanos e proteoglicanos. A IL-1 também interfere na síntese de proteoglicanos 
da matriz cartilagínea (BUCKWALTER; MANKIN, 1997).

A primeira descrição do desenvolvimento e uso do PRP aconteceu no início de 1990, quando a ciência estava focada no desenvolvimento de "colas biológicas" (LOPEZ-VIDRIERO et al., 2010). Observou-se que estas preparações tinham propriedades de formação óssea e efeitos antiinflamatórios e antibióticos, sendo tais efeitos atribuídos principalmente às plaquetas (BIELECKI et al., 2007). As plaquetas são pequenos fragmentos citoplasmáticos anucleados, originárias dos megacariócitos da medula óssea; possuem de 5 a $7 \mu \mathrm{m}$ de diâmetro e largura inferior a $3 \mu \mathrm{m}$ (FELDMAN, 2000).

O PRP é descrito como um volume de plasma que contém uma contagem de plaquetas acima da linha de base do sangue total (MARX, 2001); segundo Anitua et al. (2004) o PRP deve ter ao menos 300.000 plaquetas por microlitro. Outros autores definem o PRP como plasma sanguíneo com uma concentração plaquetária duas a oito vezes superior à concentração normal (FORTIER, 2011; McILWRAITH, 2011).

O efeito terapêutico do PRP é decorrente principalmente da degranulação dos grânulos alpha contidos nas plaquetas. Estes possuem em seu interior fatores de crescimento (FCs), entre eles: TGF- $\beta$, PDGF, fator de crescimento vascular endotelial (VEGF), fator de crescimento epidermal (EGF), fator de crescimento endotelial derivado de plaquetas (PDEGF), fator plaquetário-4, fator de angiogênese derivado de plaquetas (PDAF), e IGF-1 (WROBLEWSKI; MEJIA; WRIGHT, 2010; KON et al., 2011; BOSWELL et al., 2012; ENGEBRETSEN et al., 2010). A liberação dos FCs ocorre principalmente na primeira hora, mas continua durante o período de vida da plaqueta (aproximadamente sete dias) (COLE et al., 2010; MCCARREL; FORTIER, 2009).

Os fatores de crescimento são importantes peptídeos sinalizadores responsáveis pela regulação do metabolismo celular, interagindo com receptores de superfície celular. Estes fatores provocamaumento da transcrição gênica e produção de proteínas que desencadeiam a proliferação e diferenciação celular, além de aumentar a produção da matriz extracelular (DAHLGREN; MOHAMMED; NIXON, 2005) e estimular a angiogênese, que facilitam o processo de reparação tecidual (BOSCH et al., 2011).

A necessidade de prévia ativação das plaquetas no PRP ainda é um tema controverso (TEXTOR; TABLIN, 2012). O PRP pode ser ativado imediatamente antes da aplicação ou alternativamente, pode ocorrer junto ou após a injeção no local de interesse. Contudo, não existe um consenso sobre o momento ideal da ativação do PRP, e até mesmo sobre sua necessidade. Além disso, também não há consenso se o PRP seria melhor ativado in vitro e aplicado posteriormente in vivo, ou se seria melhor a ativação in situ (McCARREL; FORTIER, 2009; ENGEBRETSEN et al., 2010).

Sabe-se que após a injeção de PRP existe a formação de coágulo devido à exposição das plaquetas à membrana basal das células do tecido danificado. Consequentemente, há formação de um arcabouço de fibrina que permite a migração celular para o interior da lesão, além de um mecanismo que retém os FCs (FORTIER; SMITH, 2008). Partindo desta premissa, alguns autores acreditam que o PRP possa ser injetado inativado e então ser ativado pela presença de colágeno tipo 1 do tecido danificado (FARNDALE, 2006; ENGEBRETSEN et al., 2010). Já os agentes ativadores plaquetários mais comumente estudados são: ADP, trombina, colágeno tipo1, tromboplastina, cloreto de cálcio, gluconato de cálcio, ou a combinação de dois ativadores como trombina e cloreto de cálcio. Também já foi citada a ativação com tromboxane, fator ativador de plaquetas, serotonina, epinefrina, e análogos do endoperóxido cíclico (MAIA et al., 2009).

Algumas ponderações devem ser realizadas antes da escolha do método de ativação 
plaquetária. Trombina bovina pode causar reações imunomediadas (MARX, 2004) e rápida agregação, levando à necessidade do uso de trombina autóloga ou extra-purificada. O mesmo tipo de reação já foi observado utilizando-se tromboplastina em estudo experimental com coelhos (SILVA, 2007). Apesar de Textor, Norris e Tablin (2011) considerarem como insignificante a liberação de PDGF, TGF- $\beta$ e IGF-1 após a exposição ao colágeno tipo 1 , outros autores afirmam que ele é igualmente efetivo à trombina bovina (FUFA et al., 2008). Além disso, o colágeno tipo 1 induz liberação lenta dos fatores de crescimento, o que pode trazer benefício terapêutico (FOSTER et al., 2009).

O estudo mais recente publicado sobre ativação ou não de plaquetas de equinos, comparou a porcentagem de plaquetas totalmente ativadas, com ativaçãoincerta, em repouso ou com dano irreversível em amostras de PRP puro, PRP ativado com cloreto de cálcio $\left(\mathrm{CaCl}_{2}\right)(10 \%)$ ou ativado com trombina bovina (ZANDIM et al., 2012). Nesse estudo, concluiu-se que no PRP ativado com $\mathrm{CaCl}_{2}$ existe a maior quantidade de plaquetas ativadas $(24 \%) \mathrm{em}$ relação ao PRP puro (9\%), e nas amostras tratadas com trombina bovina, houve grande porcentagem de plaquetas com dano irreversível. Os autores recomendam a utilização de PRP puro quando se faz necessário utilizá-lo na forma líquida, uma vez que além de apresentar adequada porcentagem de plaquetas ativadas, ele também possui grande porcentagem de plaquetas em repouso (41\%), que podem ser ativadas posteriormente.

\section{Métodos de obtenção dos derivados sanguíneos}

Conforme mencionado anteriormente o ACS comercial é obtido a partir da coleta asséptica de sangue venoso, em uma seringa contendo esferas de vidro cuja superfície foi modificada por incubação com sulfato de cromo (MEIJER et al., 2003). Após incubação do sangue por 24 horas a $37^{\circ} \mathrm{C}$, a seringa é centrifugada a 2500 - 4000 g por 10 minutos e o ACS é aspirado e filtrado. Alíquotas de 2 a $4 \mathrm{ml}$ são preparadas e aquelas não utilizadas imediatamente são congeladas a $-20^{\circ} \mathrm{C}$ para uso futuro. Recomendase a administração semanal do ACS por quatro semanas seguidas.

Hraha et al. (2011) compararam dois métodos comerciais de preparo de ACS utilizando sangue equino, denominados IRAP e IRAP II. O sangue de cinco animais foi coletado em tubo seco, nas seringas do IRAP e IRAP II com e sem heparina, sendo incubados por uma e 24 horas. Foram dosados nestas amostras o fator de necrose tumoral $\alpha$ (TNF- $\alpha$ ), interleucina-1 $\beta$ (IL-1 $\beta)$, interleucina- 10 , IL-1ra, IGF-1 e TGF- $\beta$. Após 24 horas de incubação ambos os produtos apresentaram altas concentrações de citocinas comparativamente ao soro controle. Os resultados também revelaram aumento nas concentrações de IL-1ra, IL-1 $\beta$, IL10 , TGF- $\beta$ após 24 horas de incubação em relação à incubação em 1 hora, havendo também aumento significativo na concentração de IL-1ra no IRAP II comparado ao IRAP. Não houve diferença nas concentrações do TNF- $\alpha$ e IGF-1 após 1 hora e 24 horas de incubação. A adição de heparina resultou em redução significativa de IGF-1, TNF- $\alpha$ e TGF- $\beta$, porém aumentou em 1,5 vezes a concentração de IL-1ra. A relação IL-1ra/IL-1 $\beta$, que é um indicativo de eficácia terapêutica, foi melhor apenas no IRAP II.

Diferentes técnicas são utilizadas para obtenção do PRP, ocasionando grandes variações na concentração de plaquetas no produto final e na disponibilidade dos fatores de crescimento presentes (ARNOCZKY; DELOS; RODEO, 2011). A variedade é com relação ao protocolo de preparo, número de plaquetas, uso de anticoagulantes, presença de leucócitos e o uso de ativadores (LOPEZ-VIDRIERO et al., 2010; TEXTOR, 2011). Entender essas diferenças é um ponto crítico para analisar resultados já publicados e decidir qual sistema utilizar (LOPEZ-VIDRIERO et al., 2010).

O processo básico para obtenção do PRP é a separação seletiva dos componentes sólidos e 
líquidos do sangue total através de uma técnica chamada plasmaférese. Baseado no princípio físico descrito pela lei de Stoke, a velocidade das partículas em um ambiente líquido em resposta a uma força gravitacional, é relativa ao diâmetro dessas partículas. Sendo assim, as plaquetas, que possuem diâmetro menor que as células das séries vermelha e branca, terão uma velocidade mais baixa em resposta à mesma força gravitacional, permitindo que as plaquetas fiquem suspensas no líquido enquanto os outros componentes sólidos do sangue precipitem (ARNOCZKY; DELOS; RODEO, 2011).

Como dito, inicialmente o PRP era obtido através de máquinas de plasmaférese. O interesse em facilitar sua obtenção e diminuir custos fez com que surgissem equipamentos automatizados, diversos protocolos e kits. O custo destes aparelhos específicos, e a possibilidade de se obter o produto em pequenas quantidades, utilizando-se centrífugas convencionais, fez com que surgissem vários outros protocolos, que embora mais trabalhosos eram mais factíveis (EFEOGLU; AKÇAY; ERTURK, 2004; VENDRAMIN et al., 2006; TEXTOR, 2011; VENDRUSCOLO et al., 2012).

Para produção do PRP, o sangue total é coletado em frascos com anticoagulante, que quelam o cálcio e previnem a agregação plaquetária pela inibição da conversão de protrombina em trombina (MARX, 2001). Embora existam inúmeros anticoagulantes, apenas dois deles dão suporte ao metabolismo necessário das plaquetas e permitem a separação sem prejuízo das mesmas: ácido citrato dextrose-A (ACD) e fosfato citrato dextrose. Tubos de citrato de sódio 3,8\% também podem ser utilizados no preparo de PRP desde que o produto não seja estocado e a aplicação seja imediata. Quando utilizados tubos contendo ACD, o PRP pode ser estocado por até 6 horas (PIGNATELLI et al., 1996; ARGÜELLES et al., 2006).
Após a coleta, o sangue total é submetido a duas centrifugações com diferentes forças gravitacionais. $\mathrm{Na}$ primeira centrifugação, o plasma com as plaquetas em suspensão é separado das células brancas e vermelhas. Na segunda centrifugação, com maior força gravitacional, é separada a parte pobre em plaquetas, sobrenadante, da parte rica em plaquetas (ARNOCZKY; DELOS; RODEO, 2011).

A diferença nas forças gravitacionais e nos kits utilizados na obtenção do PRP podem causar variações de até $50 \%$ na concentração plaquetária final, uma das explicações para os resultados clínicos conflitantes no uso do PRP. Um sistema que gera um maior número absoluto de plaquetas não é necessariamente o melhor (LOPEZ-VIDRIERO et al., 2010).

As concentrações médias de plaquetas no PRP obtidas em diferentes estudos em equinos são mostradas na Tabela 1 .

Com o intuito de verificar a repetitividade dos métodos propostos, Vendruscolo et al. (2012) testaram vários protocolos descritos na literatura para obtenção do PRP observando a influência da força $G$ e do tempo de centrifugação na concentração plaquetária e leucocitária. Os protocolos testados foram o de Carmona et al. (2007) de 120 e $240 \mathrm{~g}$, respectivamente na primeira e na segunda centrifugação, Maia et al. (2009) de 120 e 473 g, De Rossi et al. (2009) de 300 e $640 \mathrm{~g}$, Del Bue et al. (2007) de 350 e $510 \mathrm{~g}$ e um protocolo proposto de 90 e $180 \mathrm{~g}$, todos com 5 e 10 minutos de centrifugação. Os protocolos que resultaram na maior concentração plaquetária foram o de Carmona et al. (2007), concentração de 2,18 vezes com cinco minutos de centrifugação e 2,36 vezes com dez minutos, e o protocolo proposto, concentração de 2,04 vezes com cinco minutos e 2,25 vezes com dez minutos, porém a diferença não foi significativa. 
Tabela 1. Concentração média plaquetária obtida em diferentes estudos realizados em equinos, de acordo com o método de preparo do PRP.

\begin{tabular}{ccc}
\hline Autor & Método de preparo & Concentração média de plaquetas \\
\hline Maia et al. (2009) & centrifugação & 407.500 plaquetas $/ \mu 1$ \\
Bosch et al. (2011) & GPS II, Biomet* & 639.700 plaquetas $/ \mu 1$ \\
Carmona et al. (2007) & centrifugação & 250.000 plaquetas $/ \mu 1$ \\
Georg et al. (2010) & Arthrex* & $160-197 \times 10^{3}$ plaquetas $/ \mu 1$ \\
Textor, Norris e Tablin (2011) & centrifugação & 1.765 .000 plaquetas $/ \mu 1$ \\
Textor, Norris e Tablin (2011) & Harvest Smart PReP2* & 951.000 plaquetas $/ \mu 1$ \\
Vendruscolo et al. (2012) & centrifugação & 343.905 plaquetas $/ \mu 1$ \\
Textor e Tablin (2013) & E-PET* & 542.000 plaquetas $/ \mu 1$ \\
Moraes (2013) & centrifugação & 423.900 plaquetas $/ \mu 1$ \\
\hline
\end{tabular}

* Kits comerciais para o preparo do PRP.

Fonte: Elaboração dos autores.

Mais recentemente, utilizando velocidade de centrifugação de $300 \mathrm{~g}$ por cinco minutos, seguida por descanso e nova centrifugação a $700 \mathrm{~g}$ por 15 minutos, os autores obtiveram concentração média de 955.000 plaquetas / $\mu 1$ no PRP, representando um incremento de 5,8 vezes em relação à concentração plaquetária sanguínea.

A recomendação de que o concentrado de plaquetas deve conter de 3 a 5 vezes a quantidade de plaquetas do sangue total (MARX, 2004; SMITH; ROSS; SMITH, 2006) é extrapolada da medicina humana. Diferentes tecidos e diferentes espécies podem ter diferentes requerimentos para otimização da cicatrização. Logo, é inapropriado aplicar os mesmos requerimentos de um tecido para outro genericamente, assim como extrapolar resultados obtidos em espécies que não a de interesse terapêutico (MCLELLAN; PLEVIN, 2011).

Textor, Norris e Tablin (2011) testaram os efeitos dos métodos de preparo, força de cisalhamento e a exposição ao colágeno sobre liberação dos FCs utilizando seis equinos. Os métodos utilizados para produção de PRP foram o automático (Harvest Smart PReP2) e a centrifugação. Apesar das maiores concentrações terem sido obtidas com a centrifugação $\left(1.765 \times 10^{3}\right.$ plaquetas/ $\left.\mu 1\right)$, as quantidades de PDGF e TGF- $\beta$ foram maiores no método automático. Em resposta ao estímulo colágeno houve aumento dose-dependente nas concentrações de PDGF e TGF $\beta-1$, mas este aumento não representou mais que $10 \%$ do conteúdo plaquetário total destes FCs.

Piccione et al. (2010) estudaram os efeitos do armazenamento do PRP em diferentes temperaturas $\left(22^{\circ} \mathrm{C}, 8^{\circ} \mathrm{C}\right.$ e de -20 a $\left.-40^{\circ} \mathrm{C}\right)$ para avaliar a coagulação e a viabilidade. Concluíram que o tempo e a temperatura de armazenamento influenciam na coagulação, sendo preferível armazenar o PRP por poucas horas à temperatura ambiente ou mantê-lo refrigerado.

Existe variabilidade do número de leucócitos encontrados no PRP, tanto na dependência do método de obtenção empregado como em função do doador. Tanto o número absoluto quanto o relativo de leucócitos muda no PRP em comparação com aqueles encontrados no sangue periférico, e é variável com o sistema de preparo selecionado. Esta variação pode ser atribuída a vários fatores, incluindo o estado de hidratação, a inflamação (leucocitose ou leucopenia), lipemia (que aumenta a concentração de plaquetas e é influenciada pela dieta) ou ritmo circadiano (BOSWELL et al., 2012).

Não existe consenso em relação aos efeitos da presença de leucócitos no concentrado de plaquetas. 
Ao mesmo tempo em que os neutrófilos liberam citocinas pró-inflamatórias IL-1, TNF- $\alpha$, IL-6, MMP-8, MMP-9 e espécies reativas de oxigênio (EROs) que podem exacerbar o dano inicial (ANITUA et al., 2004; ZANDIM et al., 2012), as células brancas também aumentam a concentração de FCs no PRP (ZIMMERMANN et al., 2008), além de efeito antibiótico, provavelmente benéfico (MOOJEN et al., 2008; CIESLIK-BIELECKA et al., 2009). Outros estudos sugerem que o PRP com leucócitos cause mais dor local que o PRP puro (ARNOCZKY; DELOS; RODEO, 2011).

Alguns autores ressaltam na descrição de seus produtos que eles são pobres em leucócitos (PRP pobre em leucócitos) ou que tiveram os leucócitos filtrados. Contudo, é possível que um efeito positivo ou negativo não possa ser generalizado para todos os tecidos e todas as condições clínicas (ARNOCZKY; DELOS; RODEO, 2011), sendo imperativa a avaliação de cada caso em particular.

\section{O emprego dos derivados sanguíneos nas lesões} tendineas e ligamentares

Após a lesão tecidual, a reparação do tendão ocorre em três fases: inflamatória, proliferativa e de remodelamento. Na primeira fase, eritrócitos e células inflamatórias, particularmente neutrófilos, além de monócitos e macrófagos adentram o local de injúria dando início à fagocitose de material necrótico. Fatores vasoativos e quimiotáticos são liberados devido à permeabilidade vascular aumentada, iniciando a angiogênese, a estimulação de proliferação de tenócitos e o recrutamento de mais células inflamatórias. Tenócitos gradualmente migram para o local de injúria promovendo a síntese de colágeno tipo III, dando início à segunda fase. E, finalmente, na última fase haverá o remodelamento do tecido cicatricial através da organização das fibras colágenas em feixes no sentido da tensão aplicada e redução da celularidade, havendo também a síntese de grande quantidade de colágeno tipo I (SHARMA; MAFFULI, 2005).
Vários FCs presentes nas plaquetas são importantes para o desenvolvimento e manutenção da higidez do tecido tendíneo (DAHLGREN; MOHAMMED; NIXON, 2005). O TFG- $\beta$ participa de quase todas as fases da reparação tendínea, estimulando: migração celular extrínseca, regulação as proteinases, interações com a fibronectina, finalização da proliferação celular através de inibidores de quinase dependente de ciclina, e a síntese de colágeno (MOLLOY; WANG; MURRELL, 2003). Logo, após lesão do tecido tendíneo há aumento da expressão de RNAm para TGF- $\beta 1$, ocorrendo seu pico após uma semana (HSU; CHANG, 2004). Apesar do seu papel primordial durante a reparação, o TGF- $\beta$ em excesso está intimamente relacionado à fibrose e formação de cicatriz, podendo provocar desordem por deposição excessiva de colágeno (HSU; CHANG, 2004).

O PDGF é importante nos estágios iniciais da reparação, quando é rapidamente produzido e induz a síntese de outros fatores de crescimento, como o IGF-I. Estudo in vitro realizado por Yoshikawa e Abrahamsson (2001) demonstrou o papel do PDGF também no remodelamento tecidual, através da produção de proteínas colágenas, não colágenas e síntese de DNA, em dose dependente. Após ativação dos receptores desse fator de crescimento há proliferação e diferenciação de fibroblastos, deposição de colágeno e angiogênese (HSU; CHANG, 2004).

O IGF-I atua em todas as fases da reparação de tecidos, principalmente durante as fases inflamatória e proliferativa (MOLLOY; WANG; MURRELL, 2003), sendo que o pico de sua concentração ocorre após quatro semanas da lesão. Já nas duas primeiras semanas a sua concentração tecidual está $40 \%$ abaixo do observado em tecido normal (DAHLGREN; MOHAMMED; NIXON, 2005). Este fator atua estimulando a proliferação e migração de fibroblastos e outras células para o local da lesão, e também aumentando a síntese de colágeno e outras moléculas da matriz extracelular 
durante a fase de remodelamento (MOLLOY; WANG; MURRELL, 2003).

O VEGF é um potente estimulante da angiogênese. Ele atua na migração celular e proliferação, sendo mais ativo após a fase de inflamação, principalmente durante as fases de proliferação e remodelamento. A neovascularização, partindo da superfície do epitendão, promove a chegada de células, nutrientes e fatores de crescimento até a lesão. Também foi demonstrado que o fator de crescimento fibroblástico básico (bFGF) é um potente estimulante da angiogênese, migração e proliferação celular (MOLLOY; WANG; MURRELL, 2003).

Em relação aos trabalhos experimentais, a maioria dos trabalhos in vitro realizados em cultivos celulares a partir de tecido tendíneo e ligamentar, mostram como os Fcs exógenos, fornecidos com o PRP, tem uma ação benéfica na resposta celular, associada ao aumento da expressão de moléculas da $\mathrm{MEC}$, as quais conferem melhores características físicas ao tecido em recuperação (GEANEY et al., 2011). Em estudos com cultivo celular a partir de tendão flexor digital superficial (TFDS) equino, Schanabel et al. (2007) testaram o efeito do PRP, plasma pobre em plaquetas (PPP), aspirado de medula óssea, plasma e sangue total, nas concentrações de $10 \%, 50 \%$ e $100 \%$ como meios de cultura. Nas culturas com $100 \%$ de PRP houve maior expressão de RNAm para colágeno tipo I (COL1A1), colágeno tipo III (COL3A1), proporção COL1A1: COL3A1, e proteína oligomérica de matriz cartilaginosa (COMP). O mesmo resultado não foi alcançado quando utilizou-se o cultivo celular a partir de ligamento suspensor do boleto (LSB) no mesmo modelo experimental (SCHANABEL et al., 2008).

Maia et al. (2009) observaram melhora histopatológica com reparação uniforme e organizada 36 dias após a aplicação intralesional do PRP em lesões do TFDS de equinos induzidas experimentalmente com colagenase.
Bosch et al. (2011) partiram da hipótese de que a pouca vascularização dos tendões poderia ser considerada como uma das razões para o potencial de cicatrização limitado. Considerando que o fator de crescimento VEGF é um potente estimulador angiogênico, avaliaram a influência do VEGF exógeno fornecido no PRP. Neste trabalho utilizaram seis cavalos, nos quais induziram tendinite cirúrgica no TFDS nos dois membros torácicos, usando um membro como controle e o outro como tratado. Os tecidos tendíneos foram avaliados por ultrassonografia e doppler, e após eutanásia os tecidos foram submetidos à análise imunoistoquímica para fator VIII (fator de Von Willebrand), presente apenas em células endoteliais intactas e funcionais. Houve maior neovascularização nos membros tratados com PRP.

Em outro estudo de Bosch et al. (2010) lesões tendíneas foram induzidas cirurgicamente nos membros torácicos em seis equinos. Sete dias depois um dos membros recebeu uma aplicação de PRP, ficando o contralateral como controle. Os animais foram então avaliados clinicamente por 24 semanas quanto ao grau de claudicação, irregularidades no tendão e sensibilidade dolorosa, e ao final do estudo foram eutanasiados. O tecido tendíneo foi submetido à análise bioquímica, biomecânica e histológica. Nos animais tratados, o conteúdo de glicosaminoglicanos, colágeno e de celularidade foram maiores, as propriedades biomecânicas melhoraram significativamente em relação ao controle, porém na análise histológica e nas avaliações clínicas não houve diferença significativa nos resultados.

Algumas revisões de literatura e revisões sistemáticas apontam controvérsia nos resultados clínicos do PRP, quando comparados aos efeitos consistentemente positivos obtidos nos estudos experimentais. Uma das razões para a variedade nos resultados clínicos observados é a falta de padronização dos protocolos de obtenção e ativação, número de plaquetas, procedimentos de administração e tecidos alvo para o tratamento. 
Além disso, muitos estudos não tem poder estatístico para documentar efeitos devido ao pequeno número de participantes. Na Medicina humana ainda há a necessidade de mais estudos prospectivos, randomizados, controlados, duplo cego, e de duração suficiente com os requerimentos necessários para oferecer o poder apropriado. (FOSTER et al., 2009; SANCHEZ et al., 2009; TAYLOR et al., 2011).

$\mathrm{Na}$ Medicina equina a necessidade de trabalhos com alto nível de evidência e adequado delineamento experimental é ainda mais urgente, dada à escassez de resultados advindos de estudos bem construídos. A grande dificuldade econômica e a falta de possibilidade de encontrar um número ideal de participantes, que confiram poder estatístico aos resultados, tornam mais difícil a execução deste tipo de estudo (FORTIER, SMITH, 2008; TEXTOR, 2011; SMITH, McILWRAITH, 2012).

Em relação a estudos clínicos na espécie equina, podemos observar que são poucos e possuem falhas estruturais - tais como ausência de grupo controle, randomização e desenho duplo-cego, além do número reduzido de pacientes e pobreza de critérios de avaliação dos tecidos tratados- que enfraquecem significativamente o grau da evidência que produzem. Apesar destas falhas, os resultados são favoráveis, de forma geral, mas menos contundentes do que os obtidos nos estudos experimentais.

Argüelles et al. (2006) usaram concentrado autólogo de plaquetas para tratar cinco cavalos com lesões tendíneas e ligamentares, três deles com lesão do LSB e dois com lesão do TFDS. Os resultados mostraram que os animais com lesão no LSB não apresentaram mudanças ultrassonográficas evidentes, embora tivessem melhora no grau de claudicação e na resposta ao teste de flexão. Além disso, todos os animais retornaram ao nível esportivo anterior à lesão e não apresentaram recidivas até 20 meses após.

Waselau et al. (2008) trataram nove equinos com desmite em terço médio do LSB, utilizando aplicações de PRP guiadas por ultrassom, seguido por um programa de exercício. O período médio de tratamento até $o$ retorno às atividades foi de 32 semanas, sendo que todos correram pelo menos uma vez após o retorno às competições nos primeiros dois anos. Destes, cinco continuaram a correr após o terceiro ano. Os quesitos número de corridas, vitórias por corrida e vitórias totais foram comparados com dados de equinos que não apresentaram desmite e houve diferença apenas na quantidade de corridas no terceiro ano após a lesão e na quantidade de vitórias por corrida no primeiro ano, sendo os valores menores no grupo tratado.

No estudo conduzido por Castelijns et al. (2011), 11 cavalos com lesões no LSB foram tratados com injeção intralesional de PRP. Após três meses do tratamento as lesões hipoecóicas haviam se resolvido. Cinco dos 11 cavalos tratados voltaram ao nível esportivo anterior, um retornou com desempenho esportivo inferior, três foram aposentados, um morreu, e outro ainda estava convalescente ao término do estudo.

Rindermann et al. (2010) conduziram um estudo com seis equinos que apresentavam variados graus de tendinite, porém sem um grupo controle. Os resultados ultrassonográficos revelaram diminuição no percentual de área lesada, na área seccional total do tendão, melhora no grau de ecogenicidade e no alinhamento das fibras. Além disso, não houve recidiva durante o período de monitoramento (13 meses pós-lesão).

Prades et al. (2006) trataram sessenta e dois equinos e, após um período de quatro a cinco meses, cinquenta e três animais voltaram ao treinamento.

Não foram encontrados estudos que avaliem a eficácia do uso de ACS em lesões tendíneas ou ligamentares de equinos.

O emprego dos derivados sanguíneos nas lesões osteoarticulares

Os FCs contidos no PRP podem contribuir para a regeneração da cartilagem, atuando sobre 
condrócitos, MEC cartilagínea, e membrana sinovial. Dentre os diversos efeitos dos FCs sobre estes componentes: estímulo da síntese de matriz extracelular (TGF- $\beta 1$, IGF-1), diminuição da atividade catabólica da IL-1 e MMP's (IGF-1), diminuição da atividade da agrecanase (FGF-2) e aumento da proliferação de condrócitos (FGF-18) . Também, os FCs atuam sobre a membrana sinovial, ou seja, causam proliferação e fibrose sinovial, indução da quimiotaxia de leucócitos inflamatórios, indução da formação de osteófito (TGF- $\beta 1$, FGF2), indução do espessamento sinovial (FGF-18), diminuição do espessamento e inflamação da membrana sinovial (IGF-1) (FORTIER; STRAUSS; COLE, 2011).

A aplicação de PRP em lesões articulares de equinos tem sido utilizada de maneira informal, uma vez que poucos são os artigos científicos que relatam o seu uso em artropatias e que demonstram eficácia terapêutica (TEXTOR, 2011).

A utilização de PRP intralesional e intra-articular em defeitos osteocondrais induzidos em equinos, produziu tecido de reparação de melhor qualidade e menor grau de claudicação dos animais (YAMADA et al., 2012).

Clinicamente, estudo feito em equinos com OA em diferentes graus, avaliados clinicamente e radiograficamente, concluiu que duas ou três aplicações de PRP intra-articular melhoram o quadro de OA (ABELLANET; PRATES, 2009). Os autores avaliaram 42 equinos atletas de dois grupos: o primeiro composto por 12 animais com enfermidade crônica bem definida, sendo considerado controle por não responder a repouso e corticoides intra-articulares; e o segundo com 30 animais, sendo 10 casos agudos e 20 crônicos, que receberam a aplicação de PRP. Os animais foram examinados antes do tratamento, 45 dias, dois meses e quatro meses após o tratamento, sendo acompanhados por um a 3,5 anos. Dos animais controles $75 \%$ (9/12) retornaram ao nível atlético inicial e 33\% (3/9) recidivaram a lesão quando em competição. Já no grupo tratado, 70\% (21/30) voltaram ao nível atlético prévio e apenas 9,5\% $(2 / 21)$ voltaram a apresentar a lesão.

Carmona et al. (2007) utilizando concentrado de plaquetas no tratamento de OA nas articulações femorotibial, metacarpofalangeana, e do tarso observaram melhora no grau de claudicação e redução da efusão articular.

Vinte e três animais foram tratados por Prades et al. (2006) com três aplicações intra-articulares de PRP, com duas a três semanas de intervalo entre elas. Houve melhora no grau de claudicação e efusão articular.

Em outro estudo com equinos que não responderam à terapia convencional, conduzido por Carmona, López e Prades (2009), testou-se tratamento composto de três aplicações intraarticulares de PRP com um intervalo de duas semanas entre elas. Os resultados foram semelhantes aos de Prades et al. (2006) com redução no grau de claudicação, principalmente após a terceira aplicação, além da diminuição da efusão articular. A resposta terapêutica foi atribuída ao efeito analgésico e anti-inflamatório exercido pelo PRP. Além disso, acredita-se que o PRP estimule os sinoviócitos a produzirem ácido hialurônico, gerando prolongado efeito analgésico e anti-inflamatório na articulação (ANITUA et al., 2007).

Carmona e López (2011) relataram o uso de três aplicações por via intra-articular de PRP $(450 \pm 35 \mathrm{x}$ $10^{6}$ plaquetas e $9,3 \pm 1,5$ leucócitos por $\mu \mathrm{L}$ ), ativado com gluconato de cálcio (1:10) na articulação escapuloumeral de uma égua com fratura de escápula e úmero, lesão do tendão bíceps braquial e distensão da bursa, sendo o intervalo entre aplicações de duas semanas. Houve melhora no quadro clínico nas 48 horas após a primeira aplicação e a recuperação do animal em 10 semanas, sendo que o esperado era entre 18-24 semanas.

Moraes (2013) constatou que o uso intraarticular de PRP em articulações hígidas causa uma 
leve e transitória inflamação articular, caracterizada por aumento de $\mathrm{PGE}_{2}$ nas primeiras seis horas após a aplicação, além de promover o aumento do fluxo vascular da membrana sinovial. Também observou que o PRP não causou aumento das concentrações de ácido hialurônico ou condroitim sulfato no líquido sinovial destas articulações.

Na mesma linha de raciocínio, Textor, Willits e Tablin (2013) realizaram um estudo onde os efeitos do PRP foram avaliados in vivo e in vitro. No experimento conduzido in vivo, à semelhança do descrito por Moraes (2013), foi observado e caracterizado um transitório processo inflamatório, agora pelo aumento das citocinas IL-6 e TNF $\alpha$ após a administração intra-articular de PRP ativado por trombina. Ainda in vivo não foi possível detectar aumento significativo dos FCs TGF- $\beta 1$ e PDGF. Apenas no experimento conduzido in vitro o desejável incremento destes FCs ficou documentado, ainda associado à ausência de elevação das concentrações de citocinas pró-inflamatórias.

A discrepância entre os resultados observados in vivo e in vitro no estudo de Textor, Willits e Tablin (2013) corrobora com a observação feita anteriormente: estudos in vitro com o PRP apontam efeitos claramente benéficos e associados ao aumento das concentrações de FCs, enquanto estudos in vivo ainda fornecem resultados contraditórios.

Em relação ao ACS, Ferris et al. (2011) constataram que 32,2\% (255/791) dos veterinários daAssociação Americana de Veterinários de Equinos (AAEP) já haviam utilizado o produto, mas somente $21,9 \%$ o usavam com frequência. Neste estudo, o principal motivo para sua utilização relacionava-se à falta de resposta à corticoterapia intra-articular, à necessidade de tratamentos sucessivos com curto intervalo de tempo, e, finalmente à maior durabilidade do efeito terapêutico (três meses a um ano) (TEXTOR, 2011).

Com o intuito de avaliar o potencial antioxidante do ACS sobre células do líquido sinovial de equinos, Brossi, Baccarin e Massoco (2012) quantificaram por citometria de fluxo a produção de espécies reativas de oxigênio (EROs) por células estimuladas com LPS e acetato miristato de forbol (PMA), bem como por aquelas estimuladas por LPS e PMA e tratadas com ACS. Concluíram que o uso de ACS reduz significativamente a produção de EROs desencadeada pelos estímulos aplicados.

Moreira (2013) observou que a aplicação intraarticular de plasma autólogo condicionado em articulações hígidas causou efeito inflamatório leve e transitório nas primeiras 24 horas após aplicação, caracterizado por aumento de $\mathrm{PGE}_{2}$.

Frisbie et al. (2007) avaliaram os efeitos clínicos, bioquímicos e histológicos do ACS em OA induzida após a realização de defeitos osteocondrais na articulação intercárpica em 16 equinos. Após 15 dias da indução da lesão iniciouse um protocolo de exercício e nos dias 14, 21, 28 e 35 foram realizadas aplicações intra-articulares de $6 \mathrm{ml}$ de ACS no grupo tratado e $6 \mathrm{ml}$ de PBS no grupo controle. Na avaliação clínica houve melhora no grau de claudicação no grupo tratado em relação ao controle, porém não houve melhora na efusão articular, no teste de flexão articular e nas características radiográficas. $\mathrm{Na}$ análise do líquido sinovial a concentração de proteínas diminuiu significativamente, porém não houve diferença em relação ao controle, assim como nas avaliações de cor, qualidade de mucina e turbidez. A concentração de glicosaminoglicanos (GAGs) e prostaglandina $\mathrm{E}_{2}$ $\left(\mathrm{PGE}_{2}\right)$, apesar de estar menor no grupo tratado com ACS não apresentou diferença significativa. Houve aumento significativo na concentração da IL-1ra no grupo tratado. A concentração de IL-1ra aumentou também em outras articulações que não receberam aplicação direta do ACS nos animais tratados, revelando que a administração de IL-1ra estimula sua síntese endógena, fato também observado em outro estudo (FRISBIE et al., 2002). Na análise macroscópica da cartilagem houve melhora nos escores para erosão e hemorragia da membrana sinovial no grupo tratado com ACS, porém esta não foi significativa. $\mathrm{Na}$ avaliação histológica 
houve melhora significativa apenas no grau de hiperplasia da camada íntima da membrana sinovial que foi menor no grupo tratado com ACS. Nos parâmetros morfológicos da cartilagem articular como fibrilação, necrose de condrócitos, formação de condroma e perda focal de células não houve diferença entre os grupos, o que também ocorreu na análise da matriz da cartilagem articular em relação ao conteúdo de GAGs e na incorporação de $\mathrm{SO}_{4}$.

Weinberger (2008) reportou os resultados referentes ao tratamento de 262 equinos acometidos por OA com duas ou três aplicações de ACS, em diversas articulações; estes pacientes haviam sido tratados previamente com injeções intra-articulares de ácido hialurônico e/ou glicocorticóides. Doze semanas após o último tratamento com ACS, 178 animais estavam em treinamento normal e não apresentavam claudicação.

O uso de ACS é popular entre veterinários que acompanham cavalos atletas, particularmente naqueles equinos submetidos a exame antidoping. Segundo este grupo de profissionais a eficácia do ACS é reconhecida, sendo frequentemente recomendado o ACS quando o uso de corticosteróides não mais mostra efeitos benéficos, especificamente em casos crônicos sob tratamento intra-articular regular em articulações com OA. A melhora da claudicação é geralmente esperada após a segunda aplicação, com resolução após a terceira ou quarta aplicação. A duração do efeito tem sido relatada como sendo por três meses a um ano em articulações não responsivas a outras terapias intra-articulares.

O emprego dos derivados sanguíneos nas lesões ósseas

As pesquisas envolvendo a utilização de PRP para auxiliar na reparação óssea em equinos ainda são escassas, sendo a maioria dos estudos conduzidos em outras espécies.

$\mathrm{Na}$ literatura encontra-se apenas um relato de caso de López, Carmona e Samudio (2010) que realizaram o tratamento de uma fratura escapular, causada acidentalmente por um projétil de arma de fogo, com três aplicações de PRP guiadas por ultrassom com duas semanas de intervalo. Após um mês de evolução houve redução no grau de claudicação (de 5 para 3 ) e não havia mais crepitação. Para diminuir a atrofia muscular ocasionada pela diminuição do uso do membro, o equino foi submetido a um programa gradual de exercícios e em nove meses estava completamente recuperado.

Intini (2009) realizou um estudo sobre as ações dos diversos fatores de crescimento plaquetários na reparação óssea, conforme demostrado na tabela 2 . 
Tabela 2. Diversas ações dos fatores de crescimento na reparação óssea.

\begin{tabular}{ll}
\hline Fator de crescimento & Ação nos ossos \\
\hline Fator de crescimento & Age na proliferação óssea, promovendo a formação do osso periosteal e \\
Epidermal (EGF) & $\begin{array}{l}\text { aumentando a reabsorção endosteal, em doses fisiológicas. A falta de receptores } \\
\text { para este fator de crescimento causa um atraso na ossificação primária da } \\
\text { cartilagem e atrasa o recrutamento dos osteoclastos e osteoblastos. }\end{array}$ \\
\hline
\end{tabular}

Fator de crescimento Age na proliferação e diferenciação ao induzir os preosteoblastos e osteoblastos

Fibroblástico básico (bFGF) capazes de induzir e sustentar a regeneração óssea.

Fator de crescimento Estimula células osteoblásticas em cultura a proliferarem, sintetizarem proteínas semelhante à insulina (IGF) da matriz óssea e estimulam a expressão de mRNA para a fosfatase alcalina, osteopontina e osteocalcina na matriz óssea estromal.

\section{Fator de crescimento celular Angiogênese.} endotelial derivado de

plaquetas (PDECGF)

Fator de crescimento derivado Proliferação: o efeito primário do PDGF nos ossos é relacionado a sua atividade de plaquetas (PDGF) mitogênica. Liberação controlada de PDGF no local da lesão é benéfica para a regeneração óssea.

Fator de crescimento Age como um fator de crescimento parácrino e autócrino proliferativo, afetando transformante - $\beta 1$ (TGF- $\beta 1$ ) principalmente os fibroblastos, células tronco medulares e pré-osteoblastos.

Fator de crescimento vascular Angiogênese: aumenta a vascularização nos defeitos ósseos. Também é eficaz endotelial (VEGF) para induzir a regeneração óssea em ossos irradiados.

Fonte: INTINI (2009).

O emprego dos derivados sanguíneos nas lesões musculares

Apesar das lesões musculares serem comuns em cavalos atletas, principalmente em competições que envolvem contato, corrida, salto e atividade de aceleração, sendo responsáveis por muitos dias perdidos na prática esportiva (FOSTER et al., 2009), a literatura sobre aplicação de PRP ou ACS em lesões musculares em equinos é escassa, sendo a maioria dos estudos conduzida em ratos, coelhos e humanos.

Também se deve levar em consideração que o TGF- $\beta$ presente nos alpha grânulos é um dos principais fatores de crescimento envolvidos na patogênese da fibrose muscular, fato comprovado por estudos in vitro. Devido a esta possível consequência, que pode levar a recidiva da lesão, sua utilização ainda não é rotineira nas lesões musculares (FOSTER et al., 2009).

\section{Considerações Finais}

Apesar dos já enumerados esforços para justificar e padronizar a obtenção e o emprego de hemoderivados no campo da ortopedia, não há consenso definitivo sobre qual, ou quais, componentes do sangue sejam os responsáveis pelo desencadeamento dos efeitos desejáveis. O plasma é um dos mais ricos e acessíveis tecidos do corpo, contendo, potencialmente, representantes de todas as proteínas produzidas por um indivíduo. A despeito de décadas de estudo, menos de $1 \%$ de um total estimado de 1.000 .000 de proteínas e anticorpos plasmáticos foram caracterizados. Deste $1 \%$, pouquíssimos são utilizados na clínica e a razão para isto é de fácil compreensão, mas de difícil solução: as concentrações das diferentes proteínas plasmáticas variam em mais de 10 ordens de magnitude, sendo 99\% deste total constituído por 20 grandes proteínas, que por sua abundância ofuscam a detecção de proteínas menores. 
O plasma é o proteoma humano mais complexo, rico e diverso e, portanto, o mais difícil de ser analisado. Suas proteínas e anticorpos exercem uma variedade de funções biológicas, desde a ativação da coagulação e do complemento à modulação da transmissão de sinais mediada por receptores e modulação de condições patológicas, como doenças auto-imunes.

As proteínas plasmáticas têm sido purificadas e utilizadas por décadas, com inúmeras indicações terapêuticas; vários novos derivados plasmáticos estão sendo desenvolvidos, não somente no campo da ortopedia, mas em várias áreas da terapêutica. Contudo, permanece o maior desafio ao pleno desenvolvimento do potencial do plasma, que é a utilização ampla de seus inúmeros componentes e a identificação de sua atividade biológica relevante. A descoberta de proteínas com novas atividades permitirá sua aplicação na terapêutica clínica.

Ainda, ao se fazer uso de hemoderivados é importante lembrar que fatores fisiológicos individuais, tais como estresse, sono, treinamento esportivo, dieta e gestação, conforme já demonstrado, levam a alterações na composição de proteínas e peptídeos plasmáticos, nos colocando mais distantes do objetivo de padronizar os produtos derivados do sangue.

Apesar da necessidade de melhor caracterização dos hemoderivados, eles têm mostrado efeitos benéficos no tratamento de várias enfermidades musculoesqueléticas, melhorando a reparação tecidual, diminuindo o número de recidivas da lesão e o tempo necessário para a volta às competições. Particularmente, quanto às afecções musculares e ósseas, ainda há poucos estudos em equinos para que sua utilização seja recomendada.

Com base na análise dos trabalhos realizados na espécie equina é possível verificar a escassez de estudos clínicos com adequado delineamento experimental, o que impossibilita a indicação incontestável do uso de hemoderivados para o tratamento de afecções musculoesqueléticas nesta espécie. Há, contudo, um montante corpo de evidências favoráveis, ainda que esparsas e basicamente no campo experimental, ao emprego dos hemoderivados no cenário da terapêutica ortopédica, que justifica a necessidade de futuros esforços para melhor fundamentar seu emprego.

\section{Referências}

ABELLANET, I.; PRADES, M. Intraarticular platelet rich plasma (PRP) therapy: evaluation in 42 sport horses with OA. In: INTERNATIONAL CONGRESS OF WORLD EQUINE VETERINARY ASSOCIATION, 11., 2009, Guarujá. Proceedings... Guarujá: Tec Art Editora Ltda, 2009. CD-ROM.

ANITUA, E.; ANDIA, I.; ARDANZA, B.; NURDEN, P.; NURDEN, A. T. Autologous platelets as a source of proteins for healing and tissue regeneration. Thrombosis and Haemostasis, Stuttgart, v. 91, n. 1, p. 4-15, 2004.

ANITUA, E.; SÁNCHEZ, M.; NURDEN, A. T.; ZALDUENDO, M. M.; DE LA FUENTE, M.; AZOFRA, J.; ANDÍA, J. Platelet-released growth factors enhance the secretion of hyaluronic acid and induce hepatocyte growth factor production by synovial fibroblasts from arthritic patients. Rheumatology, London, v. 46, n. 12, p. 1769-1772, 2007.

AREND, W. P.; MALYAK, M.; GUTHRIDGE, C. J.; GABAY, C. Interleukin-1 receptor antagonist: role in biology. Annual Review in Immunology, Palo Alto, v. 16, n. 1, p. 27-55, 1998.

ARGÜELlES, D.; CARMONA, J. U.; PASTOR, J.; IBORRA, A.; VIÑALS, L; MARTÍNEZ, P.; BACH, E.; PRADES M. Evaluation of single and double centrifugation tube methods for concentrating equine platelets. Research in Veterinary Science, Penicuik, v. 81, n. 2, p. 237-245, 2006.

ARNOCZKY, S. P.; DELOS, D.; RODEO, S. A. What is platelet-rich plasma? Operative Techniques in Sports Medicine, Philadelphia, v. 19, n. 3, p. 142-148, 2011.

BIELECKI, T. M.; GAZDZIK, T. S.; ARENDT, J.; SZCZEPANSKI, T.; KROL, W.; WIELKOSZYNSKI, T. Antibacterial effect of autologous platelet gel enriched with growth factors and other active substances: An in vitro study. The Journal of Bone Joint Surgery, Needham, v. 89, n. 3, p. 417-420, 2007.

BOSCH, G.; MOLEMAN, M.; BARNEVELD, A.; VAN WEEREN, P. R.; VAN SCHIE, H. T. The effect of platelet-rich plasma on the neovascularization of surgically created equine superficial digital flexor tendon 
lesions. Scandinavian Journal of Medicine Science and Sports, Oxford, v. 21, n. 4, p. 554-561, 2011.

BOSCH, G.; VAN SCHIE, H. T. M.; GROOT, M. W.; CADBY, J. H.; VAN DE LEST, C. H. A.; BARNEVELD, A.; VAN WEEREN, P. R. Effects of platelet-rich plasma on the quality of repair of mechanically induced core lesions in equine superficial digital flexor tendons: a placebo-controlled experimental study. Journal of Orthopaedic Research, Oxford, v. 28, n. 2, p. 211-217, 2010.

BOSWELL, S. G.; COLE, B. J.; SUNDMAN, E. A.; KARAS, V.; FORTIER, L. A. Platelet-Rich plasma: a milieu of bioactive factors. Arthroscopy, Winston-Salem, v. 28, n. 3, p. 429-439, 2012.

BROSSI, P. M.; BACCARIN, R. Y. A.; MASSOCO, C. O. Do blood components affect the production of reactive oxygen species (ROS) by equine synovial cells in vitro? Pesquisa Veterinária Brasileira, Seropédica, v. 32, n. 12, p. 1355-1360, 2012.

BUCKWALTER, J. A.; MANKIN, H. J. Articular cartilage. Part I: tissue design and chondrocyte-matrix interactions. The Journal of Bone \& Joint Surgery, Needham, v. 79, n. 4, p. 600-611, 1997.

CARMONA, J. U.; LÓPEZ, C. Autologous platelet concentrates as a treatment for shoulder injury in a horse. Journal of Equine Veterinary Science, New York, v. 31, n. 9, p. 506-510, 2011.

CARMONA, J. U.; ARGÜELLES, D.; CLIMENT, F.; PRADES, M. Autologous platelet concentrates as a treatment of horses with osteoarthritis: a preliminary pilot clinical study. Journal of Equine Veterinary Science, New York, v. 27, n. 4, p. 167-170, 2007.

CARMONA, J. U.; LÓPEZ, C.; PRADES, M. Uso de concentrados autólogos de plaquetas obtenidos mediante el método del tubo como tratamiento de artopatías em caballos. Archivos de Medicina Veterinaria, Valdivia, v. 41, n. 2, p. 175-179, 2009.

CASTELIJNS, G.; CRAWFORD, A.; SCHAFFER, J.; ORTOLANO, G. A.; BEAUREGARD, R. K. W. Evaluation of a filter-prepared platelet concentrate for the treatment of suspensory branch injuries in horses. Veterinary Comparative Orthopaedic Traumatology, Okemos, v. 24, n. 5, p. 363-369, 2011.

CIESLIK-BIELECKA, A.; BIELECKI, T.; GAZDZIK, T. S.; ARENDT, J.; KRÓL, W.; SZCZEPANSKI, T. Autologous platelets and leukocytes can improve healing of infected high-energy soft tissue injury. Transfusion and Apheresis Science, Ontaro, v. 41, n. 1, p. 9-12, 2009.

COLE, B. J.; SEROYER, S. T.; FILARDO, G.; BAJAJ, S.; FORTIER, L. A. Platelet-rich plasma: where are we now and where are we going? Sports Health, Ann Arbor, v. 2, n. 3, p. 203-210, 2010.

DAHLGREN, L. A.; MOHAMMED, H. O.; NIXON, A. J. Temporal expression of growth factors and matrix molecules in healing tendon lesions. Journal of Orthopaedic Research, Oxford, v. 23, n. 1, p. 84-92, 2005.

DE ROSSI, R.; COELHO, A. C. A. O.; MELLO, G. S.; FRAZÍLIO, F. O.; LEAL, C. R. B.; FACCO, G. G.; BRUM, K. B. Effects of platelet-rich plasma gel on skin healing in surgical wound in horses. Acta Cirurgica Brasileira, São Paulo, v. 24, n. 9, p. 276-281, 2009.

DEL BUE, M.; RICCÒ, S.; CONTI, V.; MERLI, E.; RAMONI, R.; GROLLI, S. Platelet lysate promotes in vitro proliferation of equine mesenchymal stem cells and tenocytes. Veterinary Research Communication, Midlothian, v. 31, n. 1, p. 289-292, 2007. Supplement.

EFEOGLU, C.; AKÇAY, Y. D.; ERTÜRK, S. A modified method for preparing platelet-rich plasma: an experimental study. Journal of Oral and Maxillofacial Surgery, Greenville, v. 62, n. 11, p. 1403-1407, 2004.

ENGEBRETSEN, L.; STEFFEN, K.; ALSOUSOU, J.; ANITUA, E.; BACHL, N.; DEVILLE, R.; EVERTS, P.; HAMILTON, B.; HUARD, J.; JENOURE, P.; KELBERINE, F.; KON, E.; MAFFULLI, N.; MATHESON, G.; MEI-DAN, O.; MENETREY, J.; PHILIPPON, M.; RANDELLI, P.; SCHAMASCH, P.; SCHWELLNUS, M.; VERNEC, A.; VERRALL, G. IOC consensus paper on the use of platelet-rich plasma in sports medicine. British Journal of Sports Medicine, London, v. 44, n. 15, p. 1072-1081, 2010.

FARNDALE, R. Collagen-induced platelet activation. Blood Cells, Molecules and Diseases, New York, v. 36, n. 2, p. 162-165, 2006.

FELDMAN, B. F. Schalm's veterinary hematology. 5. ed. Philadelphia: Lippincott Williams \&Wilkins; 2000.

FERRIS, D. J.; FRISBIE, D. D.; MCILWRAITH, C. W.; KAWCAK, C. E. Current joint therapy usage in equine practice: A survey of veterinarians 2009. Equine Veterinary Journal, Ely, v. 43, n. 5, p. 530-535, 2011.

FORTIER, L. A.; SMITH, R. K. W. Regenerative medicine for tendinous and ligamentous injuries of sport horses. Veterinary Clinics of North America: Equine Practice, Fort Collins, v. 24, n. 1, p. 191-201, 2008.

FORTIER, L. A.; STRAUSS, E. J.; COLE, B. J. The role of growth factors in cartilage repair. Clinical Orthopedic Related Research, Seattle, v. 469, n. 10, p. 2709-2715, 2011.

FOSTER, T. E.; PUSKAS, B. L.; MANDELBAUM, 
B. R.; GERHARDT, M. B.; RODEO, S. A. Plateletrich plasma: from basic science to clinical applications. American Journal of Sports Medicine, Rosemont, v. 37, n. 11, p. 2259-2272, 2009.

FRISBIE, D. D.; GHIVIZANNI, S. C.; ROBBINS, P. D.; EVANS, C. H.; MCILWRAITH, C. W. Treatment of experimental equine osteoarthritis by in vivo delivery of equine interleukin-1 receptor antagonist gene. Gene Therapy, Philadelphia, v. 9, n. 1, p. 12-20, 2002.

FRISBIE, D. D.; KAWCAK, C. E.; WERPY, N. M.; PARK, R. D.; MCILWRAITH, C. W. Clinical, biochemical, and histologic effects of intra-articular administration of autologous conditioned serum in horse with experimentally induced osteoarthritis. American Journal of Veterinary Research, Schaumburg, v. 68, n. 3, p. 290-296, 2007.

FUFA, D.; SHEALY, B.; JACOBSON, M.; KEVY, S.; MURRAY, M. M. Activation of platelet-rich plasma using soluble type I collagen. Journal Oral Maxillofacial Surgery, Greenville, v. 66, n. 4, p. 684-690, 2008.

GEANEY, L. E.; ARCIERO, R. A.; DEBERARDINO, T. M.; MAZZOCCA, A. D. The effects of platelet-rich plasma on tendon and ligament: basic science and clinical application. Operative Techniques in Sports Medicine, Oxford, v. 19, n. 3, p. 160-164, 2011.

GEORG, R.; MARIA, C.; GISELA, A.; BIANCA, C. Autologous conditioned plasma as therapy of tendon and ligament lesions in seven horses. Journal of Veterinary Science, Seoul, v. 11, n. 2, p. 173-175, 2010.

HRAHA, T. H.; DOREMUS, K. M.; MCILWRAITH, C. W.; FRISBIE, D. D. Autologous conditioned serum: the comparative cytokine profiles of two commercial methods (IRAP and IRAP II) using equine blood. Equine Veterinary Journal, Ely, v. 43, n. 5, p. 516-521, 2011.

HSU, C.; CHANG, J. Clinical implications of growth factors in flexor tendon wound healing. Journal of Hand Surgery, Philadelphia, v. 29A, n. 4, p. 551-563, 2004.

INTINI, G. The use of platelet-rich plasma in bone reconstruction therapy. Biomaterials, North Carolina, v. 30, n. 28, p. 4956-4966, 2009.

KON, E.; FILARDO, G.; DI MARTINO, A.; MARCACCI, M. Platelet-rich plasma (PRP) to treat sports injuries: evidence to support its use. Knee Surgery Sports Traumatology and Arthroscopy, Berlin, v. 19, n. 4, p. 516-527, 2011.

LÓPEZ, C.; CARMONA, J. U.; SAMUDIO, I. Uso de concentrados autólogos de plaquetas como tratamiento de una fractura escapular y una lesión del plexo braquial producidas por un disparo en un caballo. Archivos de Medicina Veterinaria, Valdivia, v. 42, n. 3, p. 209-214,
2010.

LOPEZ-VIDRIERO, E.; GOULDING, K. A.; SIMON, D. A.; SANCHEZ, M.; JOHNSON, D. H. The use of platelet-rich plasma in arthroscopy and sports medicine: optimizing the healing environment. Arthroscopy, Winston-Salem, v. 26, n. 2, p. 269-278, 2010.

MAIA, L.; SOUZA, M. V.; RIBEIRO JÚNIOR, J. I.; OLIVEIRA, A. C.; ALVES, G. E. S.; BENJAMIN, L. A.; MOREIRA, J. C. L. Platelet-Rich plasma in the treatment of induced tendinopathy in horses: Histologic Evaluation. Journal of Equine Veterinary Science, New York, v. 29, n. 8, p. 618-626, 2009.

MARX, R. E. Platelet-rich plasma (PRP): what is PRP and what is not PRP? Implant Dentistry, Wayne, v. 10, n. 4, p. 225-228, 2001.

. Platelet-rich plasma: evidence to support its use. Journal of oral and maxillofacial surgery, Greenville, v. 62, n. 4, p.489-496, 2004.

MCCARREL, T.; FORTIER, L. Temporal growth factor release from platelet-rich plasma, trehalose lyophilized platelets, and bone marrow aspirate and their effect on tendon and ligament gene expression. Journal of Orthopaedic Research, Oxford, v. 27, n. 8, p. 1033-1042, 2009.

McILWRAITH, C. W. Principles and practices of joint disease treatment. In: ROSS, M. W.; DYSON, S. J. Diagnosis and management of lameness in the horse. Philadelphia: Elsevier, 2011. p. 840-852.

MCLELLAN, J.; PLEVIN, S. Evidence-based clinical question does it matter which platelet-rich plasma we use? Equine Veterinary Education, Ely, v. 23, n. 2, p. 101-104, 2011.

MEIJER, H.; REINECKE, J.; BECKER, C.; THOLEN, G.; WEHLING, P. The production of anti-inflammatory cytokines in whole blood by physico-chemical induction. Inflammation Research, Montreal, v. 52, n. 10, p. 404407, 2003.

MOLLOY, T.; WANG, Y.; MURRELL, G. A. C. The roles of growth factors in tendon and ligament healing. Sports Medicine, New York, v. 33, n. 5, p. 381-94, 2003.

MOOJEN, D. J.; EVERTS, P. A.; SCHURE, R. M.; OVERDEVEST, E. P.; VAN ZUNDERT, A.; KNAPE, J. T.; CASTELEIN, R. M.; CREEMERS, L. B.; DHERT, W. J. Antimicrobial activity of platelet-leukocyte gel against Staphylococcus aureus. Journal of Orthopaedic Research, Oxford, v. 26, n. 3, p. 404-410, 2008.

MORAES, A. P. L. Resposta ao uso intra-articular do plasma rico em plaquetas em equinos hígidos: aspectos clínicos, laboratoriais e ultrassonográficos. 2013. 
Dissertação (Mestrado em Medicina Veterinária) - Curso de Pós-graduação em Clínica Veterinária. Faculdade de Medicina Veterinária e Zootecnia. Universidade de São Paulo, São Paulo.

MOREIRA, J. J. Avaliação dos efeitos da utilização de plasma autólogo condicionado em articulações sinoviais hígidas de equinos. 2013. Dissertação (Mestrado em Medicina Veterinária) - Curso de Pós-Graduação em Clínica Veterinária. Faculdade de Medicina Veterinária e Zootecnia. Universidade de São Paulo, São Paulo.

PICCIONE, G.; CASELLA, S.; GIANNETTO, C.; ASSENZA, A.; CAOLA, G. Effect of different storage conditions on platelet aggregation in horse. Journal of Equine Veterinary Science, New York, v. 30, n. 7, p. 371$375,2010$.

PIGNATELLI, P.; PULCINELLI, F. M.; CIATTI, F.; PESCIOTTI, M.; FERRONI, P.; GAZZANIGA, P. P. Effects of storage on in vitro platelet responses: comparison of $\mathrm{ACD}$ and $\mathrm{Na}$ citrate anticoagulated samples. Journal of Clinical Laboratory Analysis, Richmont, v. 10, n. 3, p. 134-139, 1996.

PRADES, M.; ABELLANET, I.; CARMONA, J. U.; ARGÜELLES, D.; MASRI, M. Platelet rich plasma: a realistic alternative in tissue repair. In: ANNUAL MEETING EUROPEAN COLLEGE OF VETERINARY SURGEONS, 15., 2006, Seville. Proceedings... Seville: ECVS, p. 211-216, 2006.

RINDERMANN, G.; CISLAKOVA, M.; ARNDT, G.; CARSTANJEN, B. Autologus conditioned plasma therapy of tendon and ligament lesions in seven horses. Journal of Veterinary Science, Seoul, v. 11, n. 2, p. 173175, 2010.

SANCHEZ, M.; ANITUA, E.; ORIVE, G.; MUJIKA, I.; ANDIA, I. Platelet-rich therapies in the treatment of orthopaedic sport injuries. Sports Medicine, New York, v. 39, n. 5, p. 345-354, 2009.

SCHANABEL, L. V.; MOHAMMED, H. O.; JACOBSON, M. S.; FORTIER, L. A. Effect of plateletrich plasma and acellular bone marrow on gene expression patterns and DNA content of equine suspensory ligament explant cultures. Equine Veterinary Journal, Ely, v. 40, n. 3, p. 260-265, 2008.

SCHANABEL, L. V.; MOHAMMED, H. O.; MILLER, B. J.; MCDERMOTT, W. G.; JACOBSON, M. S.; SANTANGELO, K. S.; FORTIER, L. A. Platelet rich plasma (PRP) enhances anabolic gene expression patterns in flexor digitorium superficialis tendon. Journal of Orthopaedic Research, Oxford, v. 25, n. 2, p. 230-240, 2007.

SHARMA, P.; MAFFULLI, N. Tendon injury and tendinopathy: healing and repair. Journal of Bone Joint Surgery, Needham, v. 87, n. 1, p. 187-202, 2005.

SILVA, P. S. A. Plasma rico em plaquetas (PRP) associado ou não ao osso esponjoso autógeno no reparo de falhas ósseas experimentais. 2007. Dissertação (Mestrado em Medicina Veterinária) - Curso de Pósgraduação em Medicina Veterinária. Universidade Federal de Viçosa, Viçosa.

SMITH, J. J.; ROSS, M. W.; SMITH, R. K. Anabolic effects of acellular bone marrow, platelet rich plasma, and serum on equine suspensory ligament fibroblasts in vitro. Veterinary and Comparative Orthopaedics and Traumatology, Okemos, v. 19, n. 1, p. 43-47, 2006.

SMITH, R. K.; MCILWRAITH, C. W. Consensus on equine tendon disease: building on the 2007 Havemeyer symposium. Equine Veterinary Journal, Ely, v. 44, n. 1, p. 2-6, 2012.

TAYLOR, D. W.; PETRERA, M.; HENDRY, M.; THEODOROPOULOS, J. S. A systematic review of the use of platelet-rich plasma in sports medicine as a new treatment for tendon and ligament injuries. Clinical journal of sport medicine, London, v. 21, n. 4, p. 344352, 2011.

TEXTOR, J. Autologous biologic treatment for equine musculoskeletal injuries: platelet-rich plasma and IL-1 receptor antagonist protein. Veterinary Clinics of North America: Equine Practice, Fort Collins, v. 27, n. 2, p. 275-298, 2011.

TEXTOR, J. A.; NORRIS, J. W.; TABLIN, F. Effects of preparation method, shear force, and exposure to collagen on release of growth factors from equine platelet-rich plasma. American Journal of Veterinary Research, Schaumburg, v. 72, n. 2, p. 271-278, 2011.

TEXTOR, J.A.; TABLIN, F. Activation of equine plateletrich plasma: comparison of methods and characterization of equine autologous thrombin. Veterinary Surgery, Davis, v. 41, n. 7, p. 784-794, 2012.

Intra-articular use of a platelet-rich product in normal horses: clinical signs and cytologic responses. Veterinary Surgery, Davis, v. 42, n. 5, p. 499-510, 2013.

TEXTOR, J. A.; WILLITS, N. H.; TABLIN, F. Synovial fluid growth factor and cytokine concentrations after intra-articular injection of a platelet-rich product in horses. The Veterinary Journal, Philadelphia, v. 198, n. 1, p. 217-223, 2013.

VENDRAMIN, F. S.; FRANCO, D.; NOGUEIRA, C. M.; PEREIRA, M. S.; FRANCO, T. R. Plasma rico em plaquetas e fatores de crescimento: técnica de preparo e utilização em cirurgia plástica. Revista do Colégio Brasileiro de Cirurgiões, Rio de Janeiro, v. 33, n. 1, p. 
24-28, 2006.

VENDRUSCOLO, C.P.; CARVALHO,A. M.; MORAES, L. F.; MAIA, L.; QUEIROZ, D. L.; WATANABE, M. J.; YAMADA, A. L. M.; ALVES, A. L. G. Avaliação da eficácia de diferentes protocolos de prepare de plasma rico em plaquetas para uso na medicina equina. Pesquisa Veterinária Brasileira, Seropédica, v. 32, n. 2, p. 106110, 2012.

WASELAU, M.; SUTTER, W. W.; GENOVESE, R. L.; BERTONE, A. L. Intralesional injection of platelet-rich plasma followed by controlled exercise for treatment of midbody suspensory ligament desmitis in Standardbred racehorses. Journal of American Veterinary Medical Association, Schaumburg, v. 232, n. 10, p. 1515-1520, 2008.

WEHLING, P.; MOSER, C.; FRISBIE, D. D.; MCILWRAITH, C. W.; KAWCAK, C. E.; KRAUSPE, R.; REINECKE, J. A. Autologous conditioned serum in the treatment of orthopedic diseases. Biodrugs, New York, v. 21, n. 5, p. 323-332, 2007.

WEINBERGER, T. Klinische Erfahrungen mit der anwendung von ACS/ORTHOKIN/IRAP beim pferd. Pferd Spiegel, Amsterdam, v. 11, n. 3, p. 111-114, 2008.

WROBLEWSKI, A. P.; MEJIA, H. A.; WRIGHT, V. J. Application of platelet-rich plasma to enhance tissue repair. Operative Techniques in Orthopaedics, Philadelphia, v. 20, n. 2, p. 98-105, 2010.
YAMADA, A. L. M.; CARVALHO, A. M.; OLIVEIRA, P. G. G.; FELISBINO, S. L.; QUEIROZ, D. L.; WATANABE, M. J.; HUSSNI, C. A.; ALVES, A. L. G. Plasma rico em plaquetas no tratamento de lesões condrais articulares induzidas experimentalmente em equinos: avaliação clínica, macroscópica, histológica e histoquímica. Arquivos Brasileiros de Medicina Veterinária e Zootecnia, Belo Horizonte, v. 64, n. 2, p. 323-332, 2012.

YOSHIKAWA, Y.; ABRAHAMSSON, S. Dose-related cellular effects of platelet-derived growth factor-BB differ in various types of rabbits tendon in vitro. Acta Orthopaedica Scandinavia, Lund, v. 72, n. 3, p. 287-292, 2001.

ZANDIM, B. M.; SOUZA, M. V.; MAGALHÃES, P. C.; BENJAMIN, L. A.; MAIA, L.; OLIVEIRA, A. C.; PINTO, J. O.; RIBEIRO JÚNIOR, J. I. Platelet activation: ultrastructure and morphometry in platelet-rich plasma of horses. Pesquisa Veterinária Brasileira, Seropédica, v. 32, n. 1, p. 83-92, 2012.

ZIMMERMANN, R.; RESKE, S.; METZLER, P.; SCHLEGEL, A.; RINGWALD, J.; ECKSTEIN, R. Preparation of highly concentrated and white cell-poor platelet-rich plasma by plateletpheresis. Vox Sanguinis, Vancouver, v. 95, n. 1, p. 20-25, 2008. 